\title{
Considerations for mosquito microbiome research from the Mosquito Microbiome Consortium
}

\author{
Nsa Dada ${ }^{1 *}$ (D), Natapong Jupatanakul ${ }^{2}$, Guillaume Minard ${ }^{3}$, Sarah M. Short ${ }^{4}$, Jewelna Akorli ${ }^{5}$ and \\ Luis Martinez Villegas ${ }^{6}$
}

\begin{abstract}
In the past decade, there has been increasing interest in mosquito microbiome research, leading to large amounts of data on different mosquito species, with various underlying physiological characteristics, and from diverse geographical locations. However, guidelines and standardized methods for conducting mosquito microbiome research are lacking. To streamline methods in mosquito microbiome research and optimize data quality, reproducibility, and comparability, as well as facilitate data curation in a centralized location, we are establishing the Mosquito Microbiome Consortium, a collaborative initiative for the advancement of mosquito microbiome research. Our overall goal is to collectively work on unraveling the role of the mosquito microbiome in mosquito biology, while critically evaluating its potential for mosquito-borne disease control. This perspective serves to introduce the consortium and invite broader participation. It highlights the issues we view as most pressing to the community and proposes guidelines for conducting mosquito microbiome research. We focus on four broad areas in this piece: (1) sampling/experimental design for field, semi-field, or laboratory studies; (2) metadata collection; (3) sample processing, sequencing, and use of appropriate controls; and (4) data handling and analysis. We finally summarize current challenges and highlight future directions in mosquito microbiome research. We hope that this piece will spark discussions around this area of disease vector biology, as well as encourage careful considerations in the design and implementation of mosquito microbiome research.
\end{abstract}

Keywords: Mosquito microbiome, Metabarcoding, Metagenomics, Metatranscriptomics, Recommendations for mosquito microbiome research, Microbiome data curation, Data quality, Reproducibility, Comparability, Microbial ecology

\section{Background}

The mosquito microbiome is critical for mosquito development, and it can have significant effects on vector competence, host immune system signaling, and longevity $[1-5]$. It has gained attention over the past decade for its influence on vector-borne pathogen transmission and as a potential avenue for vector-borne disease

\footnotetext{
* Correspondence: nsa.dada@nmbu.no; nsadada@yahoo.com

${ }^{1}$ Faculty of Science and Technology, Norwegian University of Life Sciences, Ås, Norway

Full list of author information is available at the end of the article
}

control. With this increasing interest, $>300$ scientific publications on mosquito microbiome research per year can now be retrieved from scientific literature databases (Fig. 1). This increase in independent mosquito microbiome studies has led to large amounts of data on different mosquito species, with various underlying physiological characteristics, and from diverse geographical locations. It would be ideal for the data generated from these studies to be curated in a centralized location, as well as collected, analyzed, and stored in a way that would facilitate quick and easy access for various

C C The Author(s). 2021 Open Access This article is licensed under a Creative Commons Attribution 4.0 International License, which permits use, sharing, adaptation, distribution and reproduction in any medium or format, as long as you give appropriate credit to the original author(s) and the source, provide a link to the Creative Commons licence, and indicate if changes were made. The images or other third party material in this article are included in the article's Creative Commons licence, unless indicated otherwise in a credit line to the material. If material is not included in the article's Creative Commons licence and your intended use is not permitted by statutory regulation or exceeds the permitted use, you will need to obtain permission directly from the copyright holder. To view a copy of this licence, visit http://creativecommons.org/licenses/by/4.0/ The Creative Commons Public Domain Dedication waiver (http://creativecommons.org/publicdomain/zero/1.0/) applies to the data made available in this article, unless otherwise stated in a credit line to the data. 
Interest in mosquito microbiome research over the past two decades

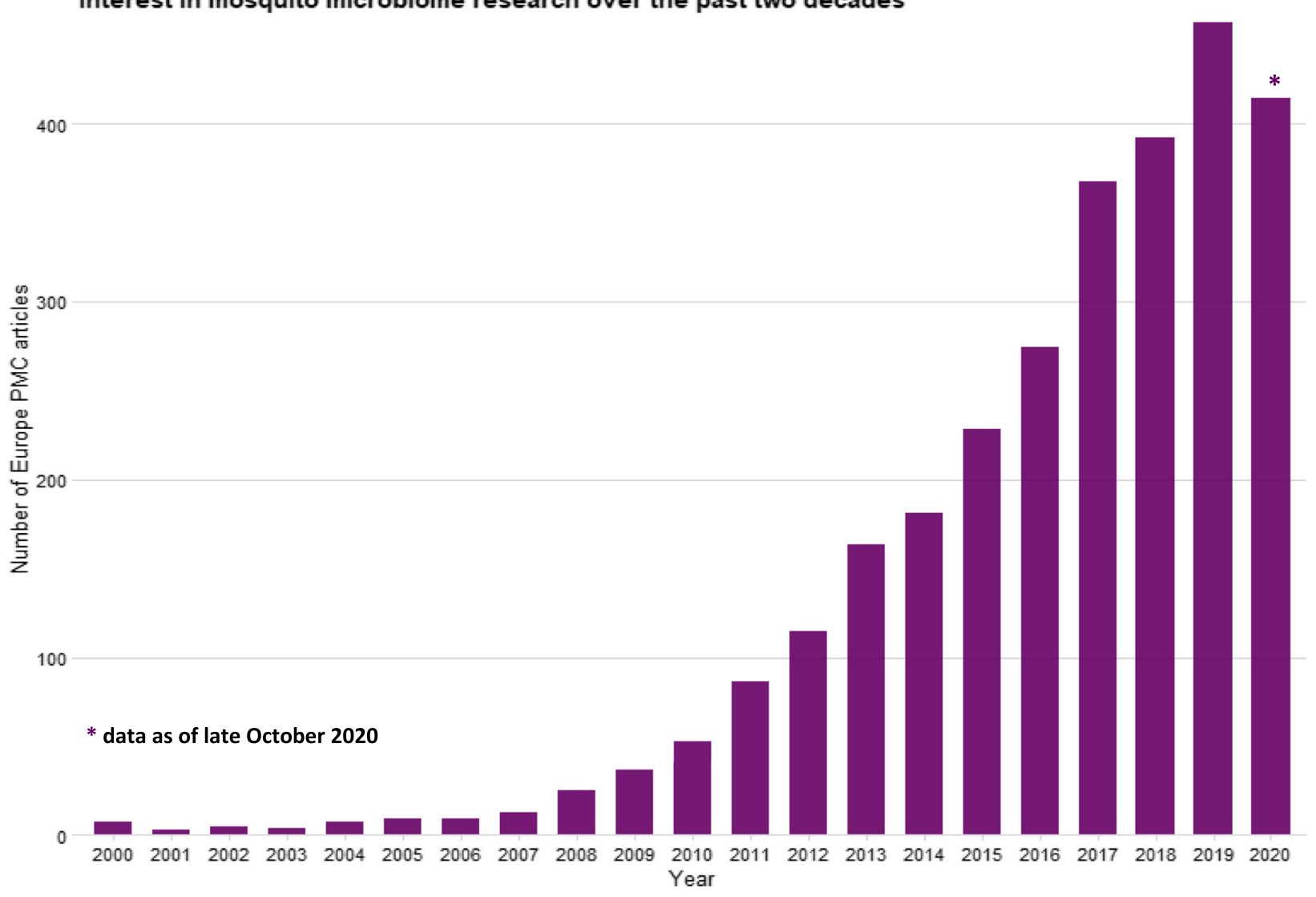

Fig. 1 Barplot showing yearly number of publications in the Europe PMC archive from 2000 to date, using search query "mosquito microbiome." The data show steadily increasing mosquito microbiome research publications over the past decade. Code for visualizing the most up to date trend is publicly available here: https://mosquito-microbiome.org/media/code-mosquito-microbiome-research-trends

purposes including new hypothesis testing, development of novel research questions, and/or meta analyses. The creation of a centralized repository would be feasible if these data followed a set of guidelines to ensure optimum quality, reliability and comparability, and adequate records of metadata, as well as appropriate and rigorous data processing and analysis. These guidelines, which can be borrowed from existing knowledge and approaches of microbiome research of other living and non-living systems [6-8], should be tailored to and designed in collaboration with the international mosquito microbiome research community.

To facilitate creation of a curated data repository as well as collaboration and discussion among mosquito microbiome scientists, we are establishing the Mosquito Microbiome Consortium (www.mosquito-microbiome. org), a collaborative initiative for the advancement of mosquito microbiome research. With an emphasis on moving mosquito microbiome research from laboratory to field, our goal as a consortium is to collectively work on unraveling the role of the mosquito microbiome in mosquito biology, while critically evaluating its potential for mosquito-borne disease control. This initial piece serves to introduce the consortium and invite broader participation. It highlights the issues we view as most pressing to the community and suggests basic guidelines for conducting mosquito microbiome research. We hope that this will elicit more discussion from the scientific community that will feed into subsequent and more comprehensive recommendations for conducting reproducible mosquito microbiome research.

\section{Proposed guidelines for mosquito microbiome research}

There are several comprehensive recommendations on best practices for microbiome studies $[9,10]$ that are very useful but not specific to the mosquito microbiome community. Gleaning from these recommendations, here we focus specifically on the mosquito microbiome and expound on specific components of the system. While there are many aspects of mosquito microbiome research that could be optimized and streamlined, we focus on four broad areas in this piece: (1) sampling/experimental design for field, semi-field, or laboratory 
studies; (2) metadata collection; (3) sample processing, sequencing, and use of appropriate controls; and (4) data handling, analysis, and deposition.

\section{Mosquito collections/experimental design for field, semi- field, or laboratory systems}

Field sampling design will be highly variable depending on research questions, but should be formulated in advance of sample collection, following similar best practices as any mosquito ecology field study [11]. Factors to consider when designing field collections for a mosquito microbiome study may include number of sites, location of sites, distance between sites, and uniform sampling methods (e.g., timing, sample collection and handling across sites, and target mosquito tissue). Where immature mosquitoes and their breeding water are desired, it would be ideal to standardize the location in the water column across sampling sites from which the latter is collected. For adult mosquito sampling, methods that allow for the collection of live mosquitoes such as mechanical aspirators [12] or frequently checked adult traps, e.g., BG-Sentinel (Biogents, Regensburg, Germany) [13] or Mosquito Magnet ${ }^{\oplus}$ (Woodstream Corporation Lititz PA), should ideally be used.

While laboratory systems can be useful for investigating physiological interactions between mosquitoes and their microbiome, or investigating mosquito microbiome dynamics in a controlled setting, they are not always ideal for all research questions, largely because results obtained using laboratory populations cannot necessarily be extrapolated to field populations. Indeed, part of the microbial diversity might be lost or altered due to the influence of environmental factors in microorganism acquisition and maintenance in laboratory conditions [14, 15]. Approaches to isolate and experimentally reintroduce microbes from field populations into laboratory colonies can improve the applicability of laboratory studies [16, 17], and several factors that should be considered for optimizing the relevance of results of mosquito microbiome laboratory experiments for field mosquito populations have been discussed by Romoli and Gendrin [18]. Regardless, when designing a mosquito microbiome study, careful consideration should be given to whether the research questions can appropriately be addressed in a laboratory system and/or whether field or semi-field experiments should be conducted.

\section{Individuals vs pools}

An important factor to consider early in the design of any mosquito microbiome study is whether individual mosquito samples or pools of mosquito samples should be processed. This decision should primarily be informed by the overall goals of the study but can also be influenced by technical and financial constraints. Pooling samples limits the ability to investigate and account for variation between individuals and the ability to assess relationships between members of the microbial community within individual mosquitoes. There are however some benefits of pooling samples, such as allowing for a larger representative sample to be taken from a population or treatment, increasing biomass which could minimize the influence of contamination [19], and a reduction in the overall number of samples to be sequenced, thereby reducing sequencing costs. When individual mosquitoes are pooled for processing, biological replicates of pools should ideally be processed. Collecting and processing biological replicates can provide insights into variation within groups or populations, but analyzing individual samples (an adequate number to provide enough statistical power) where possible would be most ideal and informative [20]. This particular decision is of utmost relevance, as the microbiome data will have three inherent characteristics that are directly affected by the pooling scheme: dimensionality (pooling creates new groups), compositionality (revealed patterns and conclusions drawn from pools may not reflect individual composition), and zero-inflated counts (low frequency and/or undetected taxa may not be uniformly distributed across pools) [21]. Ultimately, and as tested by Rodríguez-Ruano et al. [20], the microbial diversity indices will significantly be influenced by the decision taken at this methodological crossroad.

\section{Physiological characteristics}

The physiological characteristics of mosquito samples selected for microbiome studies should be properly controlled in order to avoid introducing bias and/or confounding study outcomes, as the mosquito microbiome is known to affect or be affected by host physiological status [5]. Where possible and appropriate for the study goals, the use of mosquito samples with uniform physiological characteristics should be prioritized. In laboratory settings, this can be achieved by utilizing mosquito colonies that are reared under identical conditions. In field and/or semi-field settings however, two approaches can be considered: (i) rearing progeny from field-collected mosquitoes (ideally the first filial generation) under identical laboratory conditions or (ii) rearing field-collected immature mosquitoes in water from their breeding habitats-the study objectives would determine which of the two is appropriate. In studies where none of the above outlined approaches are feasible, for example, in cases where adult field-collected mosquitoes are required, (i) an effort should be made to determine the physiological characteristics of each sample, e.g., blood fed status, size/weight, and gravid status; (ii) individuals, rather than pools, should be processed if possible; (iii) if pools are desired, individuals with similar physiological 
characteristics should be pooled; and (iv) the potential impact of variable physiological properties on the microbiota should be adequately discussed when findings of such studies are presented.

\section{Modification and manipulation of the mosquito microbiome} Some mosquito microbiome research questions may require controlled manipulation of the microbiota. Experimentally introducing microbes from field mosquitoes into laboratory colonies is a common approach for studying the effects of specific microbes on vector competence and physiology, e.g., [3, 16, 22]. Some research questions involving microbiota modification may call for the use of axenic or gnotobiotic mosquitoes. Antibiotics have been used in such studies until recently, but (i) antibiotics might directly affect the mosquito physiology or vector competence regardless of their impact on the microbiota [23], (ii) they do not fully clear the mosquito microbiota [24], and (iii) mosquitoes have been shown to harbor antibiotic-resistant microbes [25]. Recent developments in the creation of axenic and/or gnotobiotic mosquitoes $[17,26]$ offer promising solutions to these challenges and have revealed a critical role of the microbiota in larval development.

\section{Metadata}

Regardless of whether samples are collected from the field or laboratory, a comprehensive record of sample characteristics, collection, handling methods, and experimental conditions should be maintained. This would not only benefit downstream data analysis and result interpretation, but would facilitate study repeatability and/or reproducibility, and allow for subsequent data reuse and reanalysis. Based on the FAIR (Findable, Accessible, Interoperable, and Reusable) guiding principles for scientific data management and stewardship [27], a minimum information standard for reporting arthropod abundance data, MIReAD [28], has been developed. MIReAD's list and description of specific data fields that should be included in data collection sheets are relevant sample collection characteristics for mosquito microbiome studies, particularly those involving field collections. Other useful metadata standards are the Genomic Standard Consortium's minimum specifications [29, 30]. Building on these existing standards, below we describe minimum metadata records to consider for mosquito microbiome laboratory, semi-field, and field studies. We also provide a checklist of these metadata records for quick reference (Table 1), along with a ready-to-use interactive and customizable template (freely available for download here: https://mosquito-microbiome.org/ resources/mmc-white-paper/).

\section{Metadata recommendations for both field and laboratory studies}

Mosquito species Ideally, records of mosquito species should not be limited to morphological identification because some species of medical importance are nested within complexes of cryptic species that cannot be distinguished from each other, e.g., Aedes albopictus, Anopheles gambiae, and Culex pipiens [33-35]. Thus, a molecular marker should be employed to adequately identify samples-the mitochondrial cytochrome c oxidase subunit 1 (COI) gene is the most referenced molecular marker for distinguishing between eukaryotic taxa, and the Malaria Research and Reference Reagent Resource Center (MR4) provides detailed protocols for distinguishing mosquito species using the COI gene [36]. Alternatively, the internal transcribed spacer (ITS) can also be used for species identification [37].

Mosquito developmental stage/age and sex Mosquitoes develop through four stages-egg, larva, pupa, and adult, and the pupal and adult stages are sexually dimorphic and distinguishable. Records should include (a) mosquito developmental stage, as well as age for adults where possible and relevant, and (b) sex of pupae/adults. This is particularly important because the mosquito microbiome is known to be affected by these physiological characteristics or vice versa $[38,39]$. It may be difficult to determine the age of field-collected adult mosquitoes, but with new technological applications such as machine learning and infrared spectrophotometry, their age can be estimated [40]. Also, with improved annotation of sex loci in genomes of some mosquito genera [41, 42], it may be possible to distinguish between male and female eggs and larvae in the future via molecular techniques. Mosquito larvae develop through four larval instar stages (L1-L4). If larvae are used, the instar stage should be recorded where it is possible to distinguish instars. In species or cases (e.g., following preservation) where this is not possible, larval instars can be grouped as early (small, light colored, typically L1-L2) or late (larger, darker, and typically L3L4).

Mating, parity, feeding, and gonotrophic status Mosquito adult life history characteristics including mating, parity, feeding, and gonotrophic status may influence or be affected by host microbiome [43, 44]. It is thus important to record these physiological characteristics for samples when possible. These factors can easily be controlled and subsequently recorded for laboratory strains and/or progenies of field-collected mosquitoes that are reared under laboratory/controlled conditions. For example, male and female mosquitoes can be separated at 
Table 1 Checklist of minimum metadata to be collected for mosquito microbiome samples and all controls (positive and negative) processed, along with examples following existing standards of recording and reporting arthropod and genomics data. A ready-touse interactive and customizable template of these metadata records is freely available here: https://mosquito-microbiome.org/ resources/mmc-white-paper/

\begin{tabular}{|c|c|}
\hline Metadata fields & Example \\
\hline \multicolumn{2}{|l|}{ General } \\
\hline Study type & Field, semi-field, or laboratory \\
\hline Sample name & $\begin{array}{l}\text { Anopheles gambiae midgut, no template extraction/PCR control (negative control), ZymoBIOMICS } \\
\text { microbial community standard or other known mock community (positive control), etc. }\end{array}$ \\
\hline Sample ID & An_Gambiae_MG_01 \\
\hline Number per sample & Individual, pool of 3 individuals, etc. \\
\hline Sample taxonomy & Anopheles albimanus \\
\hline Developmental stage & Egg, larval instar, pupa, or adult \\
\hline Sex & Male, female, or both pooled \\
\hline $\mathrm{Age}^{\mathrm{a}}$ & 3 days post adult eclosion, $2-5$ days post eclosion etc. \\
\hline Mating status & Virgin or mated/non-virgin \\
\hline Gonotrophic status & Non-gravid, fully gravid, or half-gravid \\
\hline Blood fed & Non-blood fed or blood fed \\
\hline Type of food provided ${ }^{b}$ & 10\% sucrose, human blood, 1:3 yeast and TetraMin, etc. \\
\hline Tissue processed & Whole mosquito, midgut, ovaries, cuticle surface, etc. \\
\hline Sample phenotype & Virus/parasite infection status, insecticide resistance status, etc. \\
\hline Collection date & YYYY, YYYY-MM, or YYYY-MM-DD \\
\hline Collection time & hh, hh:mm, or hh:mm:ss \\
\hline Biomolecule processed & DNA, RNA, protein, metabolites, etc. \\
\hline Biomolecule isolation method & QIAGEN blood and tissue, phenol-chloroform, etc. \\
\hline Sequencing method & $16 \mathrm{~S}$ rRNA amplicon, whole (meta)genome, metatranscriptomic, etc. \\
\hline Sequencing platform & Illumina, Oxford Nanopore, etc. \\
\hline Sequencing platform model & MiSeq (Illumina), Minlon (Oxford Nanopore), etc. \\
\hline Sample storage preservative & None, Ethanol, RNALater , etc. \\
\hline Sample storage temperature & $-20^{\circ} \mathrm{C},-80^{\circ} \mathrm{C}$, etc. \\
\hline Sample storage duration & None, 6 months, 3 years, etc. \\
\hline \multicolumn{2}{|l|}{ Specific to field studies } \\
\hline Collection country & Nigeria \\
\hline Collection village or city & Iko Esai village \\
\hline Location coordinates & $00.000000,0000.0000$, or $00^{\circ} 00^{\prime} 00.0^{\prime \prime} \mathrm{N} 0^{\circ} 00^{\prime} 00.0^{\prime \prime} \mathrm{E}$ \\
\hline Climatic/environmental data & $27^{\circ} \mathrm{C}, 82 \% \mathrm{RH}$ \\
\hline Land cover & Savanna, urban and built up, tundra, etc. See Loveland et al. [31] for more examples \\
\hline Collection method & Human landing catch, mechanical aspirator, gravid trap, or larval dipping \\
\hline Collection bait & $\mathrm{CO} 2$, cattle \\
\hline \multicolumn{2}{|l|}{ Specific to laboratory studies } \\
\hline $\begin{array}{l}\text { Name and location of laboratory (and/or } \\
\text { facility) }\end{array}$ & $\begin{array}{l}\text { The Short Lab, College of Food, Agricultural, and Environmental Sciences, The Ohio State University, } \\
\text { Columbus, OH, USA }\end{array}$ \\
\hline Strain & STECLA, KISUMU, ROCKEFELLER \\
\hline Generation & F1, F6, F59, etc. \\
\hline Maintenance temperature & $27 \pm 2^{\circ} \mathrm{C}$ \\
\hline Maintenance relative humidity & $80 \pm 10 \%$ \\
\hline Light-dark cycle & 10-h light; 14-h dark \\
\hline
\end{tabular}


Table 1 Checklist of minimum metadata to be collected for mosquito microbiome samples and all controls (positive and negative) processed, along with examples following existing standards of recording and reporting arthropod and genomics data. A ready-touse interactive and customizable template of these metadata records is freely available here: https://mosquito-microbiome.org/ resources/mmc-white-paper/ (Continued)

\begin{tabular}{|c|c|}
\hline Metadata fields & Example \\
\hline \multicolumn{2}{|l|}{ Specific to semi-field studies } \\
\hline $\begin{array}{l}\text { Name and location of semi-field facility (if } \\
\text { widely used/known) }\end{array}$ & $\begin{array}{l}\text { MalariaSphere, Mbita Point Research \& Training Center, International Centre of Insect Physiology and } \\
\text { Ecology, Mbita, Kenya [32] }\end{array}$ \\
\hline Type of semi-field structure & Glass house, mesh house, mesh cage, etc. \\
\hline Dimensions of semi-field structure & $00.00 \times 00.00 \mathrm{~m}$ \\
\hline
\end{tabular}

aay not apply to field-derived mosquitoes

${ }^{\mathrm{b}}$ Not applicable to field-derived mosquitoes

the pupal stage to obtain virgin adults if mating and parity need to be controlled, type of food and length of time post feeding can be controlled, and gonotrophic cycle can be observed post blood-feeding. For field-collected mosquitoes, while the gonotrophic status can be determined by examining the abdomens of collected female mosquitoes, other physiological characteristics may be challenging to obtain. Determining these other physiological characteristics may require the removal and microscopic examination of specific tissues, e.g., female spermatheca and ovaries for mating and parity status $[45,46]$ or a newer non-invasive procedure as described for Ae aegypti [47], and the use of metabolomic or metabarcoding approaches to determine food sources [48-51]. The former may be feasible where these specific tissues are targeted for the microbiome study, and the latter, where it is possible to extend laboratory processes to incorporate metabarcoding/metabolomics.

Tissue/organ studied To date, mosquito microbiome studies have focused on entire individuals $[52,53]$, the alimentary canal $[15,54-59]$, salivary glands [56, 60], and/or reproductive tissues $[24,56]$, with a recent study extending microbially characterized mosquito tissues to the cuticle surface [61, 62]. Since many members of the mosquito microbiome show tissue tropism $[39,61]$, it is important to report what specific tissues are being analyzed, where applicable, or that whole samples where processed.

Storage and handling conditions Sample storage conditions have been shown to introduce variability in microbiome studies [63]. Thus, the preservation method used (e.g., buffer, preservative, temperature) along with storage duration, including any freeze-thaw cycles and/ or transportation chains (e.g., transportation on ice/dry ice/ambient temperature), should be recorded for each study. Study objectives and available resources would influence the choice of sample storage and handling, and previous research on how different methods affect insect microbiomes, e.g., $[20,64,65]$, could inform these decisions. Irrespective of chosen methods, each study should ideally use a single storage method to prevent the introduction of batch effects. Where this is not possible, for example when working with historical samples, batch effect should be accounted for during data analysis and its effect subsequently discussed.

Sample processing, sequencing, and controls Each sample processing step, the type of sequencing approach employed, along with the type of controls included in each step should be recorded. The Genomic Standard Consortium's minimum specifications $[29,30]$ can be used as a baseline.

\section{Metadata recommendations that are specific to field studies}

Location It is essential to record the origin and/or collection site of mosquito samples, as the mosquito microbiome is known to vary spatially [53, 66, 67]. These records would facilitate study replication, reproducibility, and/or spatiotemporal analysis. In addition to the location name, the GPS coordinates of mosquito collection sites should be recorded with the most precise geodetic system. The best choice is often the local system which can subsequently be converted into international standards for example using the World Geodetic System. It should be noted that while the collection or breeding sites of immature mosquitoes represent sample origin, this might not be the case for adult mosquitoes, as some species can fly up to $50 \mathrm{~km}$ from their breeding sites [68]. Thus, for field-collected adults, sampling location, rather than sample origin, should be indicated in the metadata records.

Climatic and environmental data As with location, the mosquito microbiome shows seasonal $[69,70]$ and environmental [71] variation. Thus, where possible and applicable, climatic and environmental data such as temperature, humidity, atmospheric pressure, land cover, and proximity to human dwellings should be recorded. The environmental type (e.g., breeding water or 
atmospheric) and geographic scale (e.g., microscale data collected with a data logger or macroscale data collected from a meteorological station) to which the data applies should also be indicated, along with the time scale over which the data apply. For larval breeding sites, water quality indicators can also be recorded, including $\mathrm{pH}$, total dissolved solids, and salinity, in addition to land cover information of the surrounding area. Where climatic data or land cover data are collected from national or international databases [72], these should be indicated.

Collection method The type of collection method or tool used for sample collection can influence the type and characteristics of mosquitoes collected [73, 74]. Thus, methods that are appropriate for the target species, life stage, and physiological characteristics should be employed and recorded. Each study should ideally employ a single sample collection method to avoid introducing bias. Some points to consider when collecting samples are described in the "Mosquito collections/experimental design for field, semi-field, or laboratory systems" section above.

\section{Metadata recommendations that are specific to laboratory studies}

Mosquito strains Although environmental factors appear to be a major driver of mosquito microbiome composition, some studies also show the contribution of host genetic characteristics [57, 67, 75-77]. Different mosquito genotypes may have different microbial compositions due to genetic variation in host physiological or immunological traits, or the vertical transmission of symbionts [44, 77-79]. Thus, the mosquito strains used should be reported, particularly if they are well documented and broadly used. If the strains are more specific to the laboratory or the experiment, their origin and the process used to generate and maintain them should be reported.

Filial generation and maintenance of mosquito strains During laboratory experiments, mosquito strains are often maintained over several generations. Vertically transmitted symbionts could be maintained over multiple generations, but environmentally or horizontally acquired symbionts are likely to be lost [62]. Reporting the filial generation of mosquito strains used would inform any variation that occurs in the mosquito microbiome. In addition to the number of generations, it would be valuable to report conditions and methods used in maintaining the mosquito strains. Examples of such conditions include: egg dessication between generations, synchronized egg hatching (using a vacuum for example), egg disinfection (for example with bleach solution), type of water used for breeding, larval diet recipe, and source of blood for adult feeding. These factors would inform any shifts in microbial community composition across generations.

\section{Metadata recommendations that are specific to semi-field studies}

Semi-field characteristics play an important role in mosquito physiology and behavior [80, 81], both of which are known to affect or be affected by the mosquito microbiome $[2,4]$. Thus, in addition to metadata collected for field or laboratory studies (depending on the mosquito source), semi-field characteristics should be recorded. These should include the description and dimensions of the semi-field structure or the name, along with a reference of the facility if it is widely known and used (e.g., the semi-field system at Ifakara Health Institute, Kilombero, Tanzania [81], or MalariaSphere at the International Centre of Insect Physiology and Ecology, Mbita, Kenya [32]).

\section{Sample processing, sequencing, and use of appropriate controls}

Isolating and processing the microbiome from biological samples involve several steps including sample handling, nucleic acid/peptide/metabolite isolation, purification, amplification (where necessary), identification, and sequencing. All these steps can be accomplished in-house using commercially available kits, in-house generated methods, or a combination of the two. Alternatively, all or some of the steps (commonly the sequencing step as the machines are usually expensive to own) can be outsourced to commercially available facilities. While the method of choice would depend on research questions and available resources, each study should ideally employ the same methods for all samples to avoid the introduction of batch effects. Samples should also be handled and processed to avoid the introduction of extraneous microbes. Below, we describe sample processing steps in detail, highlighting points to consider for optimal quality and comparability.

\section{Sample handling and preservation}

After collection, samples should be handled to minimize alterations to the microbial communities, and/or nucleic acid degradation prior to isolation. This requires some planning ahead. In some cases, immediate freezing of samples at $-20^{\circ} \mathrm{C}$ or lower using a freezer, dry ice, or liquid nitrogen may be possible. Alternatively, whole samples or dissected target tissues can immediately be homogenized and stored in lysis buffer or commercial nucleic acid preservative. In the field where immediate storage may not be possible, live samples can be 
collected and transported to the laboratory or field station for proper storage-immature mosquitoes should ideally be transported in their breeding water. Sample handling and preservation methods may differ depending on target biological macromolecule. For example, methods that are adequate for preserving the DNA and amino acid contents of biological samples may not be adequate to preserve RNA. Thus, sample handling and preservation should be carefully considered, and decided upon prior to sample collection.

\section{Isolation and purification of microbial genetic material}

The methods used for isolating and purifying genetic material would largely be determined by the study objective, genetic material of interest, and intended sequencing approach. These factors thus need to be carefully considered in selecting appropriate methods. Nucleic acids and proteins are largely targeted for microbiome studies, and currently, three main sequencing methods are widely employed: metabarcoding (targeting 16S rRNA/18S rRNA/ITS genes), metagenomic, and metatranscriptomic sequencing. The isolation and purification methods would differ by type of nucleic acid, as well as targeted genetic material. For instance, in metabarcoding where the universal bacterial and archaeal 16 S rRNA gene or eukaryotic $18 \mathrm{~S}$ rRNA gene and ITS region are selectively targeted with specific primers, contamination of mosquito genetic material may not be an issue. However, for metagenomic as well as metatranscriptomic sequencing, the outputs could be dominated by the genetic material of the mosquito host whose genomes-ranging from 0.098 to $1.8 \mathrm{~GB}$ [82] - can be larger by several orders of magnitude compared to that of mosquito-associated microbes. In this case, the nucleic acid isolation and purification step could be (depending on study objectives) approached such that the mosquito cells/tissues are selectively digested, and/or microbial cells/DNA are enriched prior to nucleic acid isolation and purification [83-87]. The selective digestion of eukaryotic host cells/tissues is especially possible for studies where prokaryotic microbial communities are the focus, as it may have minimal impact on the prokaryotic cells. A similar approach of selectively targeting prokaryotic RNA [88] can be employed for metatranscriptomic studies.

Both in-house protocols and commercially available nucleic acid isolation kits have been used in microbiome studies [89]. However, to reduce contamination and allow for reproducibility, commercially available kits are preferable. Irrespective of preference, the protocol selected should be appropriate for isolating the genetic material of targeted microbial components, as nucleic acid isolation and purification protocols vary in their efficiency depending on template biological material [90].
In addition, one nucleic acid isolation and purification method should ideally be employed for processing all samples within a study, as results of microbiome composition analyses have been shown to vary by nucleic acid isolation methods [91-93].

\section{Sequencing ('omics) approaches}

As earlier mentioned, metabarcoding, metagenomic, and metatranscriptomic sequencing, in addition to metaproteomics, are employed in microbiome studies. While metabarcoding involves sequencing of amplified gene targets to describe the composition of microbial communities, the other approaches provide the same insights, along with functional characterization of the microbial communities, but without the biases of targeted gene amplification. Well-curated and regularly updated reference databases based on commonly targeted microbial genetic markers (e.g., the SILVA ribosomal RNA gene database project [94]) allow for high taxonomic resolution with metabarcoding. In contrast, it can be challenging to accurately infer taxonomic origin using other 'omics approaches, such as shotgun metagenomics and metatranscriptomics due to limited well-curated databases. However, these 'omics approaches provide broader and more informative outcomes including functional catalogs, and expression profiles, in addition to taxonomic annotation of the community members. The choice of sequencing approach for mosquito microbiome studies should thus be carefully selected based on research objectives as well as the strengths and weaknesses of the different approaches $[9,95]$. As with other microbiome studies, mosquito microbiome studies have predominantly focused on 16S rRNA amplicon gene sequencing. This approach and its associated data analysis tools are thus widespread and easily accessible [96-102]. In other disciplines, there have been increasing shifts from descriptions of microbial community composition to using other 'omics tools to infer and understand the functions of microbial communities [103-105]. However, the mosquito microbiome research community is only just beginning to utilize these other 'omics approaches to understand the functions of the mosquito microbiome and its role in vectorial capacity $[83,106-$ 108].

\section{Appropriate controls}

In conducting any microbiome study, care must be taken to avoid the introduction of any extraneous microbes, as this can invalidate study outcomes. This can be accomplished by working under sterile conditions, and processing blank controls (no sample or template) along with samples at each sample processing step, to capture potential contamination by extraneous microbes [19, 109-111]. Each mosquito microbiome study should 
include blank controls at each of the following steps where applicable: sample collection (including surface sterilization and dissection where applicable), nucleic acid isolation and purification, PCR amplification, and library preparation. Controls from a previous step should be processed as a sample in subsequent steps in addition to new controls for that step, and ideally controls should be used for each batch of samples processed where they are not all processed at the same time/by the same person (batch processing should be avoided as much as possible, unless processing and/or sequencing samples in multiple batches are necessary to account for or estimate a specific parameter identified in advance). Where feasible, and especially important for high-throughput sample processing, positive controls (i.e., mock microbial community or template) should be included to optimize and validate each of these steps, as well as to capture any extraneous and cross-contamination. It is important to note that the blanks may not pass pre-sequencing quality control procedures due to absence of or low microbial load; however, they should be sequenced irrespective of whether they pass the pre-sequencing quality control or not. Several studies have shown that blanks that do not present bands following PCR and/or fail the pre-sequencing quality control step result in sequences $[83,112]$ that can subsequently be excluded from samples in downstream analysis $[57,113]$. All steps taken to minimize contamination, along with any contamination captured, should be reported in published studies.

\section{Biological and technical replicates}

The use of biological replicates has been highlighted in the "Mosquito collections/experimental design for field, semi-field, or laboratory systems" section (Individuals vs pools), but bears repeating as results without biological replicates are inconclusive due to failure to account for heterogeneity and/or variability in the samples or population. While technical replicates may be optional, depending on the research question [114], biological replicates are not [115]. The number of replicates would depend on the research questions, approach used, and, in some cases, available resources. If in doubt, a statistician or bioinformatician (specializing in microbiome studies) should be consulted during the study design.

\section{Data processing, analysis, and deposition}

Irrespective of system, the same overarching principles of processing, analyzing, and depositing microbiome data apply. Several review articles, including those by Knight et al. [9], Hongzhe [116], and Morgan and Huttenhower [117], discuss available methods for analyzing microbiome data. These reviews categorize analysis by 'omics approach and provide strengths and limitations of the methods discussed. There is a plethora of tools available for analyzing microbiome data for example phyloseq [102], mothur [101], QIIME2 [118], Anvi'o [119], and MEGAN6 [120, 121], most of which require some knowledge of programming, and this could pose a challenge for mosquito microbiome research (see below). Web-based and/or graphical user interface (GUI) versions of some of these tools, which require little or no programming knowledge, are available or are in different stages of development. For example, the Galaxy platform [122] offers a variety of tools for analyzing microbiome data. For an example guide to statistical analysis in microbial ecology, see Buttigieg and Ramette [123]. Like metadata, a good record of each data processing and analysis step, along with any codes/scripts used, should be kept. These along with the metadata and sequences (including those of controls) should be made publicly available upon study publication. Different public repositories, along with instructions for data deposition, are available; the most popular ones include the NCBI Sequence Read Archive [124], EMBL-EBI European Nucleotide Archive [125], and the NIG DNA Data Bank of Japan [126]. If studies are properly conducted, "negative" or "unexpected" results should not preclude publication of the data, as several journals now specialize in publishing genomic data.

\section{Future directions and challenges in mosquito microbiome research}

Studies showing how the mosquito microbiome influences mosquito physiological characteristics, including vectorial capacity $[3,18]$, life history traits $[16,17]$, blood meal digestion, fecundity [127], and insecticide resistance [61, 83], highlight different perspectives of mosquito-microbe interactions that are being further explored as new avenues for mosquito and mosquitoborne disease control. Standardized methods for conducting mosquito microbiome research, along with a well-curated repository of mosquito microbiome data, would expand the application of mosquito microbiome studies even further. Below are some future directions, along with some of the challenges of mosquito microbiome research:

i. Mosquito microbiota as indicators of host life history. As indicated by studies on habitat/location [53, 128-130], food source [43], age [131], infection status [18], and insecticide resistance [61, 83], more comprehensive research on the mosquito microbiome, particularly covering wider geographical locations and more mosquito species, could potentially be used to determine the ecological and physiological life histories of fieldcollected mosquitoes. It is relevant to highlight current research on how environmental change and 
human activities are influencing epidemiologically relevant mosquito behaviors [132-134]. So far, one published study on the links between the larval ecology of malaria vectors and malaria transmission has incorporated larval microbiota [71]. The extent to which the mosquito microbiome reflects or is involved in these ecological and epidemiological dynamics requires more attention.

ii. Microbiome immune priming of mosquitoes against pathogens. Although studies have demonstrated that the mosquito microbiome influences vector competence for malaria parasites and dengue viruses [22, 135-138], the direct impact of collective microbiome-induced immune activation (microbiome immune priming) on vector competence is much less described. Immune priming, driven by specific microbes, has however been demonstrated in mosquitoes [137, 139-146]. With this existing knowledge, and those of specific mosquito immune responses that control pathogen infection, particularly against malaria parasites [137], future research could extend to collective microbiome immune priming and its effect on vector competence. This knowledge could be further exploited for disrupting pathogen infections in mosquito populations, as recently shown in dengue control using Wolbachia strain wAlbB [138].

iii. Mosquito microbiome as vehicles of pathogen transmission disruption. Natural mosquito symbionts are readily able to colonize and inhabit the mosquito host. They can colonize specific host tissues [56], and can be vertically transmitted, including those that affect the fate of pathogens within mosquitoes, e.g., Serratia marcescens [147], making them suitable candidates for paratransgenesis [148]. Rapid advances in genetic engineering technologies $[149,150]$ make paratransgenesis a promising tool for disrupting the development of pathogens within the mosquito host, and significant advances have already been made for malaria parasite infections [151, 152]. More work targeting additional pathogens and particularly concentrating on field mosquito populations is required in this area.

iv. Microbiome-derived metabolites for mosquito-borne disease control. The diverse mosquito microbiome provides a microbial repertoire that can be explored for metabolites or enzymes with anti-pathogen and/ or mosquitocidal activity [153], with recent studies identifying antimalarial [154], antibiotic [155], and insecticidal $[156,157]$ compounds from the mosquito microbiota. As seen in microbiome research in other systems such as plants [158] and humans [159], an advancement in this area would include connecting mosquito microbe-derived metabolites to their biosynthetic gene clusters as exemplified by Ganley et al. [160]. Expanding research efforts towards harnessing the strengths of bioinformatics in combination with functional 'omics tools such as metatranscriptomics, metaproteomics, and metabolomics would drive this area of mosquito microbiome research forward. In addition, this area of research would also benefit from a well-curated mosquito microbiome data repository that also includes data on biosynthetic gene clusters from mosquito-associated microbes.

v. Mosquito microbiome for mosquito population suppression. Mosquito-derived microbes have long been considered for mosquito population suppression $[161,162]$, and advances in this area of research have resulted in field applications of mosquito endosymbionts for mosquito population suppression. So far, Wolbachia spp. have been employed [163-165] with varying outcomes. Briefly, the introduction of exogenous (from other mosquito/insect species) Wolbachia endosymbionts into mosquitoes decreases male mosquitoes' ability to reproduce with natural females, a method called "Incompatible Insect Technique" (see Lees et al. [166] for a review). Another widely used mosquitocidal microorganism is the entomopathogenic bacteria Bacillus thuringiensis subspecies israelensis. When sporulating, this gram-positive bacterium produces both deltaendotoxins (cry) and hemolytic factors (cyt) with high larvicidal activity against Aedes, Culex, and Anopheles mosquito species [167]. Further work to dissect interactions between mosquito microbiome and mosquito life history traits could uncover new natural mosquito symbiont candidates for mosquito population suppression.

vi. Updated 'omics approaches and expansion beyond the prokaryotic component of the microbiome. Mosquito microbiome research would benefit from expansion to non-prokaryotic components, including non-pathogenic and insect specific viruses, phages, fungi, and other eukaryotic microbes, that have largely been neglected. Growing evidence demonstrates that these non-prokaryotic microbes may play important roles in mosquito biology and vector competence [168-170]. Mosquito microbiome studies using different 'omics approaches and those focusing on neglected microbes are still evolving, with currently limited available reference genomes for mosquito-associated microbes [160]. Future efforts should be directed towards augmenting the number of available reference genomes for mosquito-associated microbes and/or identifying currently available orthologs from other systems. 
This would subsequently facilitate the use of 'omics tools other than metabarcoding for deeper insights into the role of the mosquito microbiome, and better resolution of taxonomic annotation-as the accuracy of taxonomic delineation using currently available metabarcoding tools (e.g., 16S rRNA gene) is limited [171]. There also needs to be a shift from our current practice of merely describing mosquito microbiome composition to incorporating how this composition affects different host characteristics; this is slowly changing with increasing access to molecular tools.

vii. Better understanding of the complex mosquito microbiota interactions and networks. Mosquito microbiome research is limited by our scant understanding of the complexity of the mosquito microbiome [57, 172-174], the complex interactions between the microbes, as well as interactions between the microbial network [175], the mosquito host and the pathogens which may infect them. Microbes reside in mosquito tissues as a community [56], and may need to be present as a community to affect mosquito physiology. Studies that have investigated the relationship between the mosquito microbiome and some aspects of host physiology uncover relationships that are challenging to parse, as it is unclear whether the microbiome influences a physiological outcome, vice versa or both $[2,83]$. This offers opportunities for future work to unravel these complex interactions.

viii. Unraveling the determinants of mosquito microbiome composition. Some studies suggest that the environment may be a major determinant of mosquito microbiome composition [176, 177], while others suggest a highly dynamic composition that is controlled by several factors $[66,178]$ including host species $[52,71,76]$. In addition, multiple studies have documented inter-individual variations among field-collected mosquitoes [52, 57, $172,174]$. And while some studies have also demonstrated this variation in laboratory-reared mosquitoes $[75,77,179]$, others have shown little to no variation [54]. Taken together, this presents several hypotheses pointing towards either a niche-, function-, evolutionary-, or stochastically determined microbiome [70, 180-183]. A large role for stochasticity could pose problems for mosquito microbiome manipulations in the field or the use of the microbiome as a predictive variable for modeling vector-borne disease transmission. High priority should therefore be placed on improving our understanding of the determinants of mosquito microbiome composition. ix. Biological validation of mosquito microbiome findings. Another challenge in mosquito microbiome research is limited biological validation of results and inferences. This largely requires culturable bacteria, and large portions of the mosquito microbiome are non-culturable [83, 172, 184, 185]. Employing synthetic biology to transfer genes from non-culturable microbes into culturable symbionts could be one way to address this limitation. While synthetic biology may offer a way around this limitation, data on the role of the microbiome in host physiology-particularly pathogen infection-is lacking for field mosquito populations (but see [186]). This could be in part due to the challenge of finding infected mosquitoes in the field, but with a concerted effort, along with streamlined methods, this could be rectified. Going forward as a community, especially as our focus shifts towards harnessing the mosquito microbiome for mosquito and mosquito-borne disease control, we need to better establish and validate, in field populations, the role of the microbiome in mosquito physiology and vectorial capacity.

x. Access to improved infrastructure and capacity. While rapid advances in, and increasing access to, molecular technologies have led to an increase in mosquito microbiome studies, analysis of the resulting data remains a major challenge, as specialized bioinformatics skills along with expensive computing resources are required. This is particularly true in parts of the world where mosquito-borne diseases are endemic. In these areas, access to advanced molecular technologies is also limited. More funding to support mosquito microbiome research, particularly for improved laboratory facilities, long-term establishment of computing resources, and bioinformatics training (in endemic countries especially), would be practical for addressing this challenge. Challenges that are inherent to microbiome sample processing and data analysis have extensively been discussed $[9,187]$; these also apply to mosquito microbiome research.

\section{Summary and conclusions}

Guidelines and standardized methods are needed for reproducibility, replicability, and comparability in mosquito microbiome research. In this perspective, we address issues that we find most pressing in mosquito microbiome research and propose some guidelines to allow for more streamlined research.

Some good practices to consider for mosquito microbiome studies include adequate design, appropriate sample collection and processing methods, inclusion of appropriate controls and replicates, and the use of up- 
to-date data analysis tools. Open data sharing principles must be adhered to. This would include appropriate deposition of collected data, including raw files, data matrices, metadata, and analysis scripts. This would particularly be useful for creating curated repositories that could be incorporated into existing microbiome or mosquito/insect genome repositories such as MicrobiomeDB [188], VectorBase [189], FlyBase [190], InsectBase [191], or i5kworkspace@NAL [192].

As a community, we would benefit from more sample/ data sharing and collaborations, and with streamlined methods, our work would be more reproducible, replicable, and comparable. This perspective serves as a starting point for streamlining mosquito microbiome research methods, and a call for researchers with interests in any aspect of this evolving vector biology niche to share their thoughts on appropriate methods for conducting mosquito microbiome research. Harmonizing research methods and creating a well-curated repository of mosquito microbiome data will provide a valuable resource that can be mined for new microbes/microbial agents for mosquito and mosquito-borne disease control. Our near-term goal is to make this mosquito microbiome data repository available and accessible to all.

\section{Acknowledgements}

We appreciate comprehensive feedback from anonymous reviewers on an earlier version of this manuscript; their suggestions have enriched this paper. The R script (https://gist.github.com/dsquintana/b512b715786088339b61 a7fb79367d5e) adapted for visualizing mosquito microbiome research trends was created by Daniel S. Quintana.

\section{Authors' contributions}

ND founded the Mosquito Microbiome Consortium, and ND, NJ, GM, JA, and LEMV conceived this piece to publicly launch the consortium. ND, NJ, GM, and SS wrote the initial draft of the paper, ND finalized the paper, and all authors reviewed and approved the final manuscript.

\section{Funding}

The consortium has not yet received any specific funding. The publication of this perspective, however, is made possible by support from the Faculty of Science and Technology, Norwegian University of Life Sciences to ND.

\section{Availability of data and materials}

More information about the Mosquito Microbiome Consortium can be found at www.mosquito-microbiome.org. The code used to generate the mosquito microbiome research trend, along with the metadata checklist and ready-touse customizable template, has been made publicly available and can be obtained from www.mosquito-microbiome.org/resources/mmc-white-paper/.

\section{Ethics approval and consent to participate}

Not applicable

\section{Consent for publication}

Not applicable

\section{Competing interests}

The authors declare no conflicts of interest.

\section{Author details}

${ }^{1}$ Faculty of Science and Technology, Norwegian University of Life Sciences, Ås, Norway. ${ }^{2}$ Protein-Ligand Engineering and Molecular Biology Research
Team, National Center for Genetic Engineering and Biotechnology, Khlong Neung, Thailand. ${ }^{3}$ Univ Lyon, Université Claude Bernard Lyon 1, CNRS, INRAE, VetAgro Sup, UMR Ecologie Microbienne, F-69622 Villeurbanne, France. ${ }^{4}$ Department of Entomology, The Ohio State University, Columbus, USA. ${ }^{5}$ Department of Parasitology, Noguchi Memorial Institute for Medical Research, University of Ghana, Accra, Ghana. 'und, Sweden.

Received: 3 November 2020 Accepted: 28 December 2020

Published online: 01 February 2021

\section{References}

1. Caragata EP, Tikhe CV, Dimopoulos G. Curious entanglements: interactions between mosquitoes, their microbiota, and arboviruses. Curr Opin Virol. 2019;37:26-36.

2. Guégan M, Zouache K, Démichel C, Minard G, Tran Van V, Potier P, et al. The mosquito holobiont: fresh insight into mosquito-microbiota interactions. Microbiome. 2018;6:49.

3. Jupatanakul N, Sim S, Dimopoulos G. The insect microbiome modulates vector competence for arboviruses. Viruses. 2014;6:4294-313.

4. Minard G, Mavingui P, Moro CV. Diversity and function of bacterial microbiota in the mosquito holobiont. Parasites Vectors. 2013;6:146.

5. Strand MR. Composition and functional roles of the gut microbiota in mosquitoes. Curr Opin Insect Sci. 2018;28:59-65.

6. Turnbaugh PJ, Ley RE, Hamady M, Fraser-Liggett CM, Knight R, Gordon Jl. The human microbiome project. Nature. 2007;449:804-10.

7. Boughner LA, Singh P. Microbial ecology: where are we now? Postdoc J. 2016;4:3-17.

8. Paliy O, Shankar V. Application of multivariate statistical techniques in microbial ecology. Mol Ecol. 2016;25:1032-57.

9. Knight R, Vrbanac A, Taylor BC, Aksenov A, Callewaert C, Debelius J, et al. Best practices for analysing microbiomes. Nat Rev Microbiol. 2018;16:410-22.

10. Pollock J, Glendinning L, Wisedchanwet T, Watson M. The madness of microbiome: attempting to find consensus "best practice" for $16 \mathrm{~S}$ microbiome. Studies. 2018;84:e2627-17.

11. Silver JB, Service MW. Mosquito ecology: field sampling methods. 2008;

12. Vazquez-Prokopec GM, Galvin WA, Kelly R, Kitron U. A new, cost-effective, battery-powered aspirator for adult mosquito collections. J Med Entomol. 2009;46:1256-9.

13. Krockel U, Rose A, Eiras AE, Geier M. New tools for surveillance of adult yellow fever mosquitoes: comparison of trap catches with human landing rates in an urban environment. J Am Mosa Control Assoc. 2006;22:229-38.

14. Coon KL, Brown MR, Strand MR. Gut bacteria differentially affect egg production in the anautogenous mosquito Aedes aegypti and facultatively autogenous mosquito Aedes atropalpus (Diptera: Culicidae). Parasites Vectors. 2016;9:375.

15. Dickson LB, Ghozlane A, Volant S, Bouchier C, Ma L, Vega-Rua A, et al. Diverse laboratory colonies of Aedes aegypti harbor the same adult midgut bacterial microbiome. Parasites Vectors. 2018;11:207.

16. Dickson LB, Jiolle D, Minard G, Moltini-Conclois I, Volant S, Ghozlane A, et al. Carryover effects of larval exposure to different environmental bacteria drive adult trait variation in a mosquito vector. Sci Adv. 2017;3:e1700585.

17. Coon KL, Vogel KJ, Brown MR, Strand MR. Mosquitoes rely on their gut microbiota for development. Mol Ecol. 2014;23:2727-39.

18. Romoli $\mathrm{O}$, Gendrin $\mathrm{M}$. The tripartite interactions between the mosquito, its microbiota and Plasmodium. Parasites Vectors. 2018;11:200.

19. Eisenhofer R, Minich JJ, Marotz C, Cooper A, Knight R, Weyrich LS. Contamination in low microbial biomass microbiome studies: issues and recommendations. Trends Microbiol. 2019;27:105-17.

20. Rodríguez-Ruano SM, Juhaňáková E, Vávra J, Nováková E. Methodological insight into mosquito microbiome studies. Front Cell Infect Microbiol. 2020; 10:86.

21. Tsilimigras MC, Fodor AA. Compositional data analysis of the microbiome: fundamentals, tools, and challenges. Ann Epidemiol. 2016;26:330-5.

22. Dennison NJ, Jupatanakul N, Dimopoulos G. The mosquito microbiota influences vector competence for human pathogens. Curr Opin Insect Sci. 2014;3:6-13.

23. Gendrin M, Rodgers FH, Yerbanga RS, Ouédraogo JB, Basáñez M-G, Cohuet $A$, et al. Antibiotics in ingested human blood affect the mosquito microbiota and capacity to transmit malaria. Nat Commun. 2015;6:5921. 
24. Hughes GL, Dodson BL, Johnson RM, Murdock CC, Tsujimoto H, Suzuki Y, et al. Native microbiome impedes vertical transmission of Wolbachia in Anopheles mosquitoes. Proc Natl Acad Sci U S A. 2014;111:12498-503.

25. Hyde J, Gorham C, Brackney DE, Steven B. Antibiotic resistant bacteria and commensal fungi are common and conserved in the mosquito microbiome. PLoS One. 2019;14:e0218907.

26. Correa MA, Matusovsky B, Brackney DE, Steven B. Generation of axenic Aedes aegypti demonstrate live bacteria are not required for mosquito development. Nat Commun. 2018;9:4464.

27. Wilkinson MD, Dumontier M, Aalbersberg IJJ, Appleton G, Axton M, Baak A, et al. The FAIR Guiding Principles for scientific data management and stewardship. Sci Data. 2016;3:160018.

28. Rund SSC, Braak K, Cator L, Copas K, Emrich SJ, Giraldo-Calderón Gl, et al. MIReAD, a minimum information standard for reporting arthropod abundance data. Sci Data. 2019:6:40

29. Yilmaz P, Kottmann R, Field D, Knight R, Cole JR, Amaral-Zettler L, et al. Minimum information about a marker gene sequence (MIMARKS) and minimum information about any $(\mathrm{x})$ sequence (MIXS) specifications. Nat Biotechnol. 2011;29:415-20.

30. Bowers RM, Kyrpides NC, Stepanauskas R, Harmon-Smith M, Doud D, Reddy TBK, et al. Minimum information about a single amplified genome (MISAG) and a metagenome-assembled genome (MIMAG) of bacteria and archaea. Nat Biotechnol. 2017;35:725-31.

31. Loveland TR, Reed BC, Brown JF, Ohlen DO, Zhu Z, Yang L, et al. Development of a global land cover characteristics database and IGBP DISCover from 1 km AVHRR data. Int J Remote Sensing. 2000;21:1303-30.

32. Knols BGJ, Njiru BN, Mathenge EM, Mukabana WR, Beier JC, Killeen GF. MalariaSphere: a greenhouse-enclosed simulation of a natural Anopheles gambiae (Diptera: Culicidae) ecosystem in western Kenya. Malar J. 2002;1:19.

33. Stevenson JC, Norris DE. Implicating cryptic and novel anophelines as malaria vectors in Africa. Insects. 2016;8:1.

34. Müller $P$, Pflüger $V$, Wittwer $M$, Ziegler $D$, Chandre F, Simard F, et al. Identification of cryptic anopheles mosquito species by molecular protein profiling. PLoS One. 2013;8:e57486.

35. Minard G, Tran Van V, Tran FH, Melaun C, Klimpel S, Koch LK, et al. Identification of sympatric cryptic species of Aedes albopictus subgroup in Vietnam: new perspectives in phylosymbiosis of insect vector. Parasites Vectors. 2017;10:276.

36. MR4. Methods in Anopheles research. Malaria Research and Reference Reagent Resource Center. 2015;

37. Wang X-C, Liu C, Huang L, Bengtsson-Palme J, Chen H, Zhang J-H, et al. ITS1: a DNA barcode better than ITS2 in eukaryotes? Mol Ecol Resour. 2015; 15:573-86.

38. Tchioffo MT, Boissière A, Abate L, Nsango SE, Bayibéki AN, Awono-Ambéné $\mathrm{PH}$, et al. Dynamics of bacterial community composition in the malaria mosquito's epithelia. Front Microbiol. 2016;6:1500.

39. David MR, Santos LM, Vicente AC, Maciel-de-Freitas R. Effects of environment, dietary regime and ageing on the dengue vector microbiota: evidence of a core microbiota throughout Aedes aegypti lifespan. Mem Inst Oswaldo Cruz. 2016;111:577-87.

40. González Jiménez M, Babayan SA, Khazaeli P, Doyle M, Walton F, Reedy E, et al. Prediction of mosquito species and population age structure using mid-infrared spectroscopy and supervised machine learning. Wellcome Open Res. 2019:4:76.

41. Matthews BJ, Dudchenko O, Kingan SB, Koren S, Antoshechkin I, Crawford $\mathrm{JE}$, et al. Improved reference genome of Aedes aegypti informs arbovirus vector control. Nature. 2018;563:501-7.

42. Waterhouse RM, Aganezov S, Anselmetti Y, Lee J, Ruzzante L, Reijnders MJMF, et al. Evolutionary superscaffolding and chromosome anchoring to improve Anopheles genome assemblies. BMC Biol. 2020;18:1.

43. Muturi EJ, Dunlap C, Ramirez IL, Rooney AP, Kim CH. Host blood-meal source has a strong impact on gut microbiota of Aedes aegypti. FEMS Microbiol Ecol. 2019;95:fiy213.

44. Wang Y, lii TMG, Kukutla P, Yan G. Xu J. Dynamic gut microbiome across life history of the malaria mosquito Anopheles gambiae in Kenya. PLOS ONE. Public Libr Sci. 2011;6:e24767.

45. Charlwood JD, Tomás EVE, Andegiorgish AK, Mihreteab S, LeClair C. "We like it wet": a comparison between dissection techniques for the assessment of parity in Anopheles arabiensis and determination of sac stage in mosquitoes alive or dead on collection. PeerJ. 2018;6:e5155.

46. Rosay B. Anatomical indicators for assessing age of mosquitoes: dissection techniques and field application of methods. Mosq News. 1969;29:419-23.
47. Carrasquilla MC, Lounibos LP. Detection of insemination status in live Aedes aegypti females. J Insect Physiol. 2015;75:1-4.

48. Champion CJ, Kukutla P, Glennon EKK, Wang B, Luckhart S, Xu J. Anopheles gambiae: metabolomic profiles in sugar-fed, blood-fed, and Plasmodium falciparum-infected midgut. Dataset Papers in Science. 2017; Article ID 8091749. https://www.hindawi.com/journals/dpis/2017/8091749/.

49. Egizi A, Healy SP, Fonseca DM. Rapid blood meal scoring in anthropophilic Aedes albopictus and application of PCR blocking to avoid pseudogenes. Infect Genet Evol. 2013;16:122-8.

50. Reeves LE, Gillett-Kaufman JL, Kawahara AY, Kaufman PE. Barcoding blood meals: new vertebrate-specific primer sets for assigning taxonomic identities to host DNA from mosquito blood meals. PLoS Negl Trop Dis. 2018;12: e0006767.

51. Santos CS, Pie MR, da Rocha TC, Navarro-Silva MA. Molecular identification of blood meals in mosquitoes (Diptera, Culicidae) in urban and forested habitats in southern Brazil. PLoS One. 2019;14:e0212517.

52. Muturi EJ, Kim C-H, Bara J, Bach EM, Siddappaji MH. Culex pipiens and Culex restuans mosquitoes harbor distinct microbiota dominated by few bacterial taxa. Parasites Vectors. 2016;9:18.

53. Muturi EJ, Lagos-Kutz D, Dunlap C, Ramirez JL, Rooney AP, Hartman GL, et al. Mosquito microbiota cluster by host sampling location. Parasites Vectors. 2018;11:468.

54. Wieland G, Neumann R, Backhaus H. Variation of microbial communities in soil, rhizosphere, and rhizoplane in response to crop species, soil type, and crop development. Appl Environ Microbiol. 2001;67:5849-54.

55. Gusmao DS, Santos AV, Marini DC, Russo Ede S, Peixoto AM, Bacci Junior M, et al. First isolation of microorganisms from the gut diverticulum of Aedes aegypti (Diptera: Culicidae): new perspectives for an insect-bacteria association. Mem Inst Oswaldo Cruz. 2007;102:919-24.

56. Mancini MV, Damiani C, Accoti A, Tallarita M, Nunzi E, Cappelli A, et al. Estimating bacteria diversity in different organs of nine species of mosquito by next generation sequencing. BMC Microbiol. 2018;18:126.

57. Minard G, TRAN F-H, Tran-Van V, Goubert C, Bellet C, Lambert G, et al. French invasive Asian tiger mosquito populations harbor reduced bacterial microbiota and genetic diversity compared to Vietnamese autochthonous relatives. Front Microbiol. 2015;6:970.

58. Terenius O, Lindh JM, Eriksson-Gonzales K, Bussiere L, Laugen AT, Bergquist $\mathrm{H}$, et al. Midgut bacterial dynamics in Aedes aegypti. FEMS Microbiol Ecol. 2012;80:556-65.

59. Wu P, Sun P, Nie K, Zhu Y, Shi M, Xiao C, et al. A gut commensal bacterium promotes mosquito permissiveness to arboviruses. Cell Host Microbe. 2019; 25:101-112.e5.

60. Sharma P, Sharma S, Maurya RK, Das De T, Thomas T, Lata S, et al. Salivary glands harbor more diverse microbial communities than gut in Anopheles culicifacies. Parasites Vectors. 2014;7:235.

61. Dada N, Lol JC, Benedict AC, López F, Sheth M, Dzuris N, et al. Pyrethroid exposure alters internal and cuticle surface bacterial communities in Anopheles albimanus. ISME J. 2019;13:2447-64.

62. Dada N, Benedict AC, López F, Lol JC, Sheth M, Dzuris N, et al. Anopheles albimanus natural microbiota is altered within one generation of laboratory colonization. bioRxiv. 2020; https://doi.org/10.1101/2020.06.02.129619.

63. Song SJ, Amir A, Metcalf JL, Amato KR, Xu ZZ, Humphrey G, et al. Preservation methods differ in fecal microbiome stability, affecting suitability for field studies. mSystems 2016;1:e00021-16.

64. Hammer TJ, Dickerson JC, Fierer N. Evidence-based recommendations on storing and handling specimens for analyses of insect microbiota. Weightman A, editor. PeerJ. 2015;3:e1190.

65. De Cock M, Virgilio M, Vandamme P, Augustinos A, Bourtzis K, Willems A, et al. Impact of sample preservation and manipulation on insect gut microbiome profiling. A test case with fruit flies (Diptera, Tephritidae). Frontiers in Microbiology. 2019;10:2833.

66. Bascuñán P, Niño-Garcia JP, Galeano-Castañeda Y, Serre D, Correa MM Factors shaping the gut bacterial community assembly in two main Colombian malaria vectors. Microbiome. 2018;6:148.

67. Rosso F, Tagliapietra V, Albanese D, Pindo M, Baldacchino F, Arnoldi D, et al. Reduced diversity of gut microbiota in two Aedes mosquitoes species in areas of recent invasion. Sci Reports. 2018;8:16091.

68. Verdonschot PFM, Besse-Lototskaya AA. Flight distance of mosquitoes (Culicidae): a metadata analysis to support the management of barrier zones around rewetted and newly constructed wetlands. Limnologica. 2014; 45:69-79. 
69. Krajacich BJ, Huestis DL, Dao A, Yaro AS, Diallo M, Krishna A, et al. Investigation of the seasonal microbiome of Anopheles coluzzii mosquitoes in Mali. PLoS One. 2018;13:e0194899.

70. Novakova E, Woodhams DC, Rodríguez-Ruano SM, Brucker RM, Leff JW, Maharaj $A$, et al. Mosquito microbiome dynamics, a background for prevalence and seasonality of West Nile virus, vol. 8; 2017.

71. Prussing C, Saavedra MP, Bickersmith SA, Alava F, Guzmán M, Manrique E, et al. Malaria vector species in Amazonian Peru co-occur in larval habitats but have distinct larval microbial communities. PLoS Negl Trop Dis. 2019;13: e0007412.

72. Morueta-Holme N, Oldfather MF, Olliff-Yang RL, Weitz AP, Levine CR, Kling $\mathrm{MM}$, et al. Best practices for reporting climate data in ecology. Nat Climate Change. 2018;8:92-4

73. Lühken R, Pfitzner WP, Börstler J, Garms R, Huber K, Schork N, et al. Field evaluation of four widely used mosquito traps in Central Europe. Parasites Vectors. 2014;7:268.

74. Cansado-Utrilla C, Jeffries CL, Kristan M, Brugman VA, Heard P, Camara G, et al. An assessment of adult mosquito collection techniques for studying species abundance and diversity in Maferinyah, Guinea. Parasites Vectors. 2020;13:150

75. Minard G, Tran F-H, Tran Van V, Fournier C, Potier P, Roiz D, et al. Shared larval rearing environment, sex, female size and genetic diversity shape Ae. albopictus bacterial microbiota. PLoS One. 2018;13:e0194521.

76. Muturi EJ, Ramirez JL, Rooney AP, Kim CH. Comparative analysis of gut microbiota of mosquito communities in central Illinois. PLoS Negl Trop Dis. 2017;11:e0005377.

77. Short SM, Mongodin EF, MacLeod HJ, Talyuli OAC, Dimopoulos G. Amino acid metabolic signaling influences Aedes aegypti midgut microbiome variability. PLoS Negl Trop Dis. 2017;11:e0005677.

78. Akhouayri IG, Habtewold T, Christophides GK. Melanotic pathology and vertical transmission of the gut commensal Elizabethkingia meningoseptica in the major malaria vector Anopheles gambiae. PLoS One. 2013;8:e77619.

79. Saridaki A, Bourtzis K. Wolbachia: more than just a bug in insects genitals. Curr Opin Microbiol. 2010;13:67-72

80. Niang A, Nignan C, Serge Poda B, Sawadogo SP, Roch Dabiré K, Gnankiné $O$, et al. Semi-field and indoor setups to study malaria mosquito swarming behavior. Parasites Vectors. 2019;12:446.

81. Ferguson HM, Ng'habi KR, Walder T, Kadungula D, Moore SJ, Lyimo I, et al. Establishment of a large semi-field system for experimental study of African malaria vector ecology and control in Tanzania. Malar J. 2008;7:158.

82. Wang X-T, Zhang Y-J, Qiao L, Chen B. Comparative analyses of simple sequence repeats (SSRs) in 23 mosquito species genomes: identification, characterization and distribution (Diptera: Culicidae). Insect Science. 2019;26: 607-19.

83. Dada N, Sheth M, Liebman K, Pinto J, Lenhart A. Whole metagenome sequencing reveals links between mosquito microbiota and insecticide resistance in malaria vectors. Sci Reports. 2018:8:2084

84. Flaherty BR, Talundzic E, Barratt J, Kines KJ, Olsen C, Lane M, et al. Restriction enzyme digestion of host DNA enhances universal detection of parasitic pathogens in blood via targeted amplicon deep sequencing. Microbiome. 2018;6:164.

85. Marotz CA, Sanders JG, Zuniga C, Zaramela LS, Knight R, Zengler K. Improving saliva shotgun metagenomics by chemical host DNA depletion. Microbiome. 2018;6:42.

86. Nelson MT, Pope CE, Marsh RL, Wolter DJ, Weiss EJ, Hager KR, et al. Human and extracellular DNA depletion for metagenomic analysis of complex clinical infection samples yields optimized viable microbiome profiles. Cell Reports. 2019;26:2227-2240.e5.

87. Belda E, Coulibaly B, Fofana A, Beavogui AH, Traore SF, Gohl DM, et al. Preferential suppression of Anopheles gambiae host sequences allows detection of the mosquito eukaryotic microbiome. Sci Reports. 2017;7: 3241.

88. Bashiardes S, Zilberman-Schapira G, Elinav E. Use of metatranscriptomics in microbiome research. Bioinformatics Biol Insights. 2016;10:19-25.

89. Birer, C, Tysklind, N, Zinger, L, Duplais, C. Comparative analysis of DNA extraction methods to study the body surface microbiota of insects: A case study with ant cuticular bacteria. Mol Ecol Resour. 2017;17: e34- e45.

90. Dineen SM, Aranda R IV, Anders DL, Robertson JM. An evaluation of commercial DNA extraction kits for the isolation of bacterial spore DNA from soil. Journal of Applied Microbiology. 2010;109:1886-96.
91. Teng F, Darveekaran Nair SS, Zhu P, Li S, Huang S, Li X, et al. Impact of DNA extraction method and targeted 16S-rRNA hypervariable region on oral microbiota profiling. Sci Reports. 2018:8:16321.

92. Gerasimidis K, Bertz M, Quince C, Brunner K, Bruce A, Combet E, et al. The effect of DNA extraction methodology on gut microbiota research applications. BMC Res Notes. 2016;9:365.

93. Videnska P, Smerkova K, Zwinsova B, Popovici V, Micenkova L, Sedlar K, et al Stool sampling and DNA isolation kits affect DNA quality and bacterial composition following 165 rRNA gene sequencing using MiSeq Illumina platform. Sci Reports. 2019;9:13837.

94. Quast C, Pruesse E, Yilmaz P, Gerken J, Schweer T, Yarza P, et al. The SILVA ribosomal RNA gene database project: improved data processing and webbased tools. Nucleic Acids Res. 2012:41:D590-6.

95. Quince C, Walker AW, Simpson JT, Loman NJ, Segata N. Shotgun metagenomics, from sampling to analysis. Nat Biotechnol. 2017;35:833-44.

96. Fadrosh DW, Ma B, Gajer P, Sengamalay N, Ott S, Brotman RM, et al. An improved dual-indexing approach for multiplexed $16 \mathrm{~S}$ rRNA gene sequencing on the Illumina MiSeq platform. Microbiome. 2014;2:6.

97. Tamaki H, Wright CL, Li X, Lin Q, Hwang C, Wang S, et al. Analysis of 16 S rRNA amplicon sequencing options on the Roche/454 next-generation titanium sequencing platform. PLoS One. 2011:6:e25263.

98. Benítez-Páez A, Portune KJ, Sanz Y. Species-level resolution of 165 rRNA gene amplicons sequenced through the MinION ${ }^{\top M}$ portable nanopore sequencer. Gigascience. 2016;5:4.

99. Lane DJ, Pace B, Olsen GJ, Stahl DA, Sogin ML, Pace NR. Rapid determination of 165 ribosomal RNA sequences for phylogenetic analyses. Proceedings of the National Academy of Sciences. 1985;82:6955-9.

100. Schloss PD, Gevers D, Westcott SL. Reducing the effects of PCR amplification and sequencing artifacts on $16 \mathrm{~S}$ rRNA-based studies. PLoS One. 2011;6:e27310

101. Schloss PD, Westcott SL, Ryabin T, Hall JR, Hartmann M, Hollister EB, et al. Introducing mothur: open-source, platform-independent, communitysupported software for describing and comparing microbial communities. Appl Environ Microbiol. 2009;75:7537-41.

102. McMurdie PJ, Holmes S. phyloseq: an R package for reproducible interactive analysis and graphics of microbiome census data. PLoS One. 2013;8:e61217.

103. Cani PD. Human gut microbiome: hopes, threats and promises. Gut. 2018; 67:1716-25.

104. Proctor L, LoTempio J, Marquitz A, Daschner P, Xi D, Flores R, et al. A review of 10 years of human microbiome research activities at the US National Institutes of Health, Fiscal Years 2007-2016. Microbiome. 2019;7:31.

105. Blaser MJ, Cardon ZG, Cho MK, Dangl JL, Donohue TJ, Green JL, et al. Toward a predictive understanding of Earth's microbiomes to address 21st century challenges. mBio. 2016;7:e00714-6.

106. Chandler JA, Liu RM, Bennett SN. RNA shotgun metagenomic sequencing of northern California (USA) mosquitoes uncovers viruses, bacteria, and fungi. Front Microbiol. 2015;6:185.

107. Shi M, Neville P, Nicholson J, Eden J-S, Imrie A, Holmes EC. Highresolution metatranscriptomics reveals the ecological dynamics of mosquito-associated RNA viruses in Western Australia. J Virol. 2017;91: e00680-17.

108. Xiao P, Li C, Zhang Y, Han J, Guo X, Xie L, et al. Metagenomic sequencing from mosquitoes in China reveals a variety of insect and human viruses. Front Cell Infect Microbiol. 2018;8:364.

109. Hornung BVH, Zwittink RD, Kuijper EJ. Issues and current standards of controls in microbiome research. FEMS Microbiol Ecol. 2019;95:fiz045.

110. Kim D, Hofstaedter CE, Zhao C, Mattei L, Tanes C, Clarke E, et al. Optimizing methods and dodging pitfalls in microbiome research. Microbiome. 2017;5:52.

111. de Goffau MC, Lager S, Salter SJ, Wagner J, Kronbichler A, Charnock-Jones DS, et al. Recognizing the reagent microbiome. Nat Microbiol. 2018;3:851-3.

112. Salter SJ, Cox MJ, Turek EM, Calus ST, Cookson WO, Moffatt MF, et al. Reagent and laboratory contamination can critically impact sequence-based microbiome analyses. BMC Biol. 2014:12:87.

113. Karstens L, Asquith M, Davin S, Fair D, Gregory WT, Wolfe AJ, et al. Controlling for contaminants in low-biomass 165 rRNA gene sequencing experiments. mSystems. 2019;4:e00290-19.

114. Marotz C, Sharma A, Humphrey G, Gottel N, Daum C, Gilbert JA, et al. Triplicate PCR reactions for $16 \mathrm{~S}$ rRNA gene amplicon sequencing are unnecessary. BioTechniques. 2019:67:29-32.

115. Prosser Jl. Replicate or lie. Environmental Microbiology. 2010;12:1806-10. 
116. Li H. Microbiome, metagenomics, and high-dimensional compositional data analysis. Annual Review of Statistics and Its Application. 2015;2:73-94.

117. Morgan XC, Huttenhower C. Chapter 12: human microbiome analysis. PLoS Comput Biol. 2012;8:e1002808.

118. Bolyen E, Rideout JR, Dillon MR, Bokulich NA, Abnet CC, Al-Ghalith GA, et al. Reproducible, interactive, scalable and extensible microbiome data science using QIIME 2. Nat Biotechnol. 2019;37:852-7.

119. Eren AM, Esen ÖC, Quince C, Vineis JH, Morrison HG, Sogin ML, et al. Anvi'o: an advanced analysis and visualization platform for 'omics data. van Gulik W, editor. PeerJ. 2015;3:e1319.

120. Huson DH, Auch AF, Qi J, Schuster SC. MEGAN analysis of metagenomic data. Genome Res. 2007;17:377-86.

121. Huson DH, Albrecht B, Bağcı C, Bessarab I, Górska A, Jolic D, et al. MEGANLR: new algorithms allow accurate binning and easy interactive exploration of metagenomic long reads and contigs. Biol Direct. 2018;13:6.

122. Afgan E, Baker D, Batut B, van den Beek M, Bouvier D, Cech M, et al. The Galaxy platform for accessible, reproducible and collaborative biomedical analyses: 2018 update. Nucleic Acids Res. 2018;46:W537-44.

123. Buttigieg PL, Ramette A. A guide to statistical analysis in microbial ecology: a community-focused, living review of multivariate data analyses. FEMS Microbiol Ecol. 2014;90:543-50.

124. Leinonen $R$, Sugawara $H$, Shumway M. International Nucleotide Sequence Database $C$. The sequence read archive. Nucleic Acids Res. 2011;39:D19-21.

125. Kanz C, Aldebert P, Althorpe N, Baker W, Baldwin A, Bates K, et al. The EMBL Nucleotide Sequence Database. Nucleic Acids Res. 2005;33:D29-33.

126. Ogasawara O, Kodama Y, Mashima J, Kosuge T, Fujisawa T. DDBJ Database updates and computational infrastructure enhancement. Nucleic Acids Res. 2020;48:D45-d50.

127. de O Gaio A, Gusmão DS, Santos AV, Berbert-Molina MA, Pimenta PFP, Lemos FJA. Contribution of midgut bacteria to blood digestion and egg production in Aedes aegypti (diptera: culicidae) (L.). Parasites Vectors. 2011; 4:105.

128. Buck M, Nilsson LKJ, Brunius C, Dabiré RK, Hopkins R, Terenius O. Bacterial associations reveal spatial population dynamics in Anopheles gambiae mosquitoes. Sci Reports. 2016;6:22806.

129. Akorli J, Gendrin M, Pels NAP, Yeboah-Manu D, Christophides GK, Wilson MD. Seasonality and locality affect the diversity of Anopheles gambiae and Anopheles coluzzii midgut microbiota from Ghana. PLoS One. 2016;11: e0157529.

130. Gimonneau G, Tchioffo MT, Abate L, Boissière A, Awono-Ambéné PH, Nsango SE, et al. Composition of Anopheles coluzzii and Anopheles gambiae microbiota from larval to adult stages. Infect Genet Evol. 2014;28: 715-24.

131. Duguma D, Hall MW, Rugman-Jones P, Stouthamer R, Terenius O, Neufeld $J \mathrm{D}$, et al. Developmental succession of the microbiome of Culex mosquitoes. BMC Microbiol. 2015;15:140.

132. Ramasamy R, Surendran SN. Global climate change and its potential impact on disease transmission by salinity-tolerant mosquito vectors in coastal zones. Front Physiol. 2012;3:198

133. Wilke ABB, Chase C, Vasquez C, Carvajal A, Medina J, Petrie WD, et al. Urbanization creates diverse aquatic habitats for immature mosquitoes in urban areas. Sci Reports. 2019;9:15335.

134. Chandrasegaran $K$, Lahondère C, Escobar LE, Vinauger C. Linking mosquito ecology, traits, behavior, and disease transmission. Trends Parasitol. 2020;36: 393-403.

135. Ramirez JL, Dimopoulos G. The Toll immune signaling pathway control conserved anti-dengue defenses across diverse Ae. aegypti strains and against multiple dengue virus serotypes. Dev Comp Immunol. 2010;34: 625-9.

136. Kalappa DM, Subramani PA, Basavanna SK, Ghosh SK, Sundaramurthy V, Uragayala $\mathrm{S}$, et al. Influence of midgut microbiota in Anopheles stephensi on Plasmodium berghei infections. Malar J. 2018;17:385.

137. Dong Y, Manfredini F, Dimopoulos G. Implication of the mosquito midgut microbiota in the defense against malaria parasites. PLoS Pathogens. 2009;5: e1000423 Public Library of Science.

138. Nazni WA, Hoffmann AA, NoorAfizah A, Cheong YL, Mancini MV, Golding N, et al. Establishment of Wolbachia strain wAlbB in Malaysian populations of Aedes aegypti for dengue control. Curr Biol. 2019;29:4241-4248.e5.

139. Dillon RJ, Dillon VM. The gut bacteria of insects: nonpathogenic interactions. Annu Rev Entomol. 2004:49:71-92.
140. Charroux B, Royet J. Drosophila immune response: from systemic antimicrobial peptide production in fat body cells to local defense in the intestinal tract. Fly. 2010;4:40-7.

141. Ryu J-H, Kim S-H, Lee H-Y, Bai JY, Nam Y-D, Bae J-W, et al. Innate immune homeostasis by the homeobox gene caudal and commensal-gut mutualism in Drosophila. Science. 2008:319:777-82 American Association for the Advancement of Science.

142. Stathopoulos S, Neafsey DE, Lawniczak MKN, Muskavitch MAT, Christophides GK. Genetic dissection of Anopheles gambiae gut epithelial responses to Serratia marcescens. PLoS Pathog. 2014;10:e1003897 Public Library of Science.

143. Rodgers FH, Gendrin M, Wyer CAS, Christophides GK. Microbiota-induced peritrophic matrix regulates midgut homeostasis and prevents systemic infection of malaria vector mosquitoes. PLoS Pathog. 2017;13:e1006391 Public Library of Science.

144. Rodgers FH, Gendrin M, Christophides GK. Chapter 6 - the mosquito immune system and its interactions with the microbiota: implications for disease transmission. In: Wikel SK, Aksoy S, Dimopoulos G, editors. Arthropod vector: controller of disease transmission, Volume 1 [Internet]: Academic; 2017. p. 101-22. [cited 2020 Oct 29]. Available from: http://www. sciencedirect.com/science/article/pii/B9780128053508000064.

145. Dimopoulos G, Christophides GK, Meister S, Schultz J, White KP, BarillasMury C, et al. Genome expression analysis of Anopheles gambiae: responses to injury, bacterial challenge, and malaria infection. PNAS. Natl Acad Sci. 2002;99:8814-9.

146. Ramirez JL, Souza-Neto J, Cosme RT, Rovira J, Ortiz A, Pascale JM, et al. Reciprocal tripartite interactions between the Aedes aegypti midgut microbiota, innate immune system and dengue virus influences vector competence. PLoS Negl Trop Dis. 2012;6:e1561 Public Library of Science.

147. Bando H, Okado K, Guelbeogo WM, Badolo A, Aonuma H, Nelson B, et al. Intra-specific diversity of Serratia marcescens in Anopheles mosquito midgut defines Plasmodium transmission capacity. Sci Reports. 2013;3:1641.

148. Mancini MV, Spaccapelo R, Damiani C, Accoti A, Tallarita M, Petraglia E, et al. Paratransgenesis to control malaria vectors: a semi-field pilot study. Parasites Vectors. 2016;9:140.

149. Tachibana C. Technology Feature | Beyond CRISPR: what's current and upcoming in genome editing. Science. 2019;365:1484.

150. Anzalone AV, Randolph PB, Davis JR, Sousa AA, Koblan LW, Levy JM, et al. Search-and-replace genome editing without double-strand breaks or donor DNA. Nature. 2019;576:149-57.

151. Wang S, Dos-Santos ALA, Huang W, Liu KC, Oshaghi MA, Wei G, et al. Driving mosquito refractoriness to Plasmodium falciparum with engineered symbiotic bacteria. Science (New York, NY). 2017;357:1399-402.

152. Shane JL, Grogan CL, Cwalina C, Lampe DJ. Blood meal-induced inhibition of vector-borne disease by transgenic microbiota. Nat Commun. 2018:9:4127.

153. Saraiva RG, Dimopoulos G. Bacterial natural products in the fight against mosquito-transmitted tropical diseases. Nat Prod Rep. 2020:37:338-54.

154. Saraiva RG, Huitt-Roehl CR, Tripathi A, Cheng Y-Q, Bosch J, Townsend CA, et al. Chromobacterium spp. mediate their anti-Plasmodium activity through secretion of the histone deacetylase inhibitor romidepsin. Sci Rep. 2018:8:6176 Nature Publishing Group.

155. Ganley JG, Carr G, loerger TR, Sacchettini JC, Clardy J, Derbyshire ER. Discovery of antimicrobial lipodepsipeptides produced by a Serratia sp. within mosquito microbiomes. ChemBioChem. 2018;19:1590-4.

156. Short SM, van Tol S, Smith B, Dong Y, Dimopoulos G. The mosquito adulticidal Chromobacterium sp. Panama causes transgenerational impacts on fitness parameters and elicits xenobiotic gene responses. Parasites Vectors. 2018:11:229.

157. Ramirez JL, Short SM, Bahia AC, Saraiva RG, Dong Y, Kang S, et al. Chromobacterium Csp_P reduces malaria and dengue infection in vector mosquitoes and has entomopathogenic and in vitro anti-pathogen activities. PLoS Pathog. 2014:10:e1004398 Public Library of Science.

158. Helfrich EJN, Vogel CM, Ueoka R, Schäfer M, Ryffel F, Müller DB, et al. Bipartite interactions, antibiotic production and biosynthetic potential of the Arabidopsis leaf microbiome. Nat Microbiol. 2018;3:909-19 Nature Publishing Group.

159. Donia MS, Cimermancic P, Schulze CJ, Wieland Brown LC, Martin J, Mitreva $M$, et al. A systematic analysis of biosynthetic gene clusters in the human microbiome reveals a common family of antibiotics. Cell. 2014;158:1402-14. 
160. Ganley JG, Pandey A, Sylvester K, Lu K-Y, Toro-Moreno M, Rütschlin S, et al. A systematic analysis of mosquito-microbiome biosynthetic gene clusters reveals antimalarial siderophores that reduce mosquito reproduction capacity. Cell Chem Biol. 2020;27:817-826.e5.

161. Benelli G, Jeffries CL, Walker T. Biological control of mosquito vectors: past, present, and future. Insects. 2016;7:52

162. Evans HC, Elliot SL, Barreto RW. Entomopathogenic fungi and their potential for the management of Aedes aegypti (Diptera: Culicidae) in the Americas. Mem Inst Oswaldo Cruz. 2018;113:206-14.

163. Rasic G, Endersby NM, Williams C, Hoffmann AA. Using Wolbachia-based release for suppression of Aedes mosquitoes: insights from genetic data and population simulations. Ecol Appl. 2014;24:1226-34.

164. Aliota MT, Walker EC, Uribe Yepes A, Dario Velez I, Christensen BM, Osorio JE. The wMel strain of Wolbachia reduces transmission of chikungunya virus in Aedes aegypti. PLoS Negl Trop Dis. 2016;10:e0004677.

165. Zheng $X$, Zhang D, Li Y, Yang C, Wu Y, Liang $X$, et al. Incompatible and sterile insect techniques combined eliminate mosquitoes. Nature. 2019;572: 56-61.

166. Lees RS, Gilles JRL, Hendrichs J, Vreysen MJB, Bourtzis K. Back to the future: the sterile insect technique against mosquito disease vectors. Curr Opin Insect Sci. 2015;10:156-62.

167. Ben-Dov E. Bacillus thuringiensis subsp. israelensis and its dipteran-specific toxins. Toxins. 2014;6:1222-43 Multidisciplinary Digital Publishing Institute.

168. Bargielowski I, Koella JC. A possible mechanism for the suppression of Plasmodium berghei development in the mosquito Anopheles gambiae by the microsporidian Vavraia culicis. PLoS One. 2009;4:e4676.

169. Angleró-Rodríguez Yl, Blumberg BJ, Dong Y, Sandiford SL, Pike A, Clayton AM, et al. A natural Anopheles-associated Penicillium chrysogenum enhances mosquito susceptibility to Plasmodium infection. Sci Reports. 2016;6:34084.

170. Herren JK, Mbaisi L, Mararo E, Makhulu EE, Mobegi VA, Butungi H, et al. A microsporidian impairs Plasmodium falciparum transmission in Anopheles arabiensis mosquitoes. Nat Commun. 2020;11:2187.

171. Janda JM, Abbott SL. 16 S rRNA Gene sequencing for bacterial identification in the diagnostic laboratory: pluses, perils, and pitfalls. J Clin Microbiol. 2007 45:2761-4 American Society for Microbiology Journals.

172. Osei-Poku J, Mbogo CM, Palmer WJ, Jiggins FM. Deep sequencing reveals extensive variation in the gut microbiota of wild mosquitoes from Kenya. Mol Ecol. 2012;21:5138-50.

173. Duguma D, Hall MW, Smartt CT, Debboun M, Neufeld JD. Microbiota variations in Culex nigripalpus disease vector mosquito of West Nile virus and Saint Louis Encephalitis from different geographic origins. Hoyles L, editor. PeerJ. 2019;6:e6168

174. Luis $P$, Vallon L, Tran F-H, Hugoni M, Tran-Van V, Mavingui $P$, et al. Aedes albopictus mosquitoes host a locally structured mycobiota with evidence of reduced fungal diversity in invasive populations. Fungal Ecol. 2019;39:25766.

175. Hegde S, Khanipov K, Albayrak L, Golovko G, Pimenova M, Saldaña MA, et al. Microbiome interaction networks and community structure from laboratory-reared and field-collected Aedes aegypti, Aedes albopictus, and Culex quinquefasciatus mosquito vectors. Front Microbiol. 2018;9:2160

176. Yun JH, Roh SW, Whon TW, Jung MJ, Kim MS, Park DS, et al. Insect gut bacterial diversity determined by environmental habitat, diet, developmental stage, and phylogeny of host. Appl Environ Microbiol. 2014; 80:5254-64.

177. Coon KL, Brown MR, Strand MR. Mosquitoes host communities of bacteria that are essential for development but vary greatly between local habitats. Mol Ecol. 2016;25:5806-26.

178. Saab SA, zu Dohna H, Nilsson LKJ, Onorati P, Nakhleh J, Terenius O, et al. The environment and species affect gut bacteria composition in laboratory co-cultured Anopheles gambiae and Aedes albopictus mosquitoes. Sci Reports. 2020;10:3352.

179. Guegan M, Minard G, Tran FH, Tran Van V, Dubost A, Valiente MC. Shortterm impacts of anthropogenic stressors on Aedes albopictus mosquito vector microbiota. FEMS Microbiol Ecol. 2018;94:fiy188.

180. Albright MBN, Chase AB, Martiny JBH. Experimental evidence that stochasticity contributes to bacterial composition and functioning in a decomposer community. mBio. 2019;10:e00568-19.

181. Brooks AW, Kohl KD, Brucker RM, van Opstal EJ, Bordenstein SR. Phylosymbiosis: relationships and functional effects of microbial communities across host evolutionary history. PLoS Biol. 2016;14:e2000225
182. Hird SM. Microbiomes, community ecology, and the comparative method mSystems. 2019;4:e00112-19.

183. Li H, Li T, Qu J. Stochastic processes govern bacterial communities from the blood of pikas and from their arthropod vectors. FEMS Microbiol Ecol. 2018. 94:fiy082.

184. Galeano-Castañeda Y, Urrea-Aguirre P, Piedrahita S, Bascuñán P, Correa MM Composition and structure of the culturable gut bacterial communities in Anopheles albimanus from Colombia. PLoS One. 2019;14:e0225833.

185. Chavshin AR, Oshaghi MA, Vatandoost H, Pourmand MR, Raeisi A, Terenius O. Isolation and identification of culturable bacteria from wild Anopheles culicifacies, a first step in a paratransgenesis approach. Parasites Vectors. 2014;7:419.

186. Boissière A, Tchioffo MT, Bachar D, Abate L, Marie A, Nsango SE, et al. Midgut microbiota of the malaria mosquito vector Anopheles gambiae and interactions with Plasmodium falciparum infection. PLoS Pathog. 2012;8: e1002742.

187. Bharti R, Grimm DG. Current challenges and best-practice protocols for microbiome analysis. Brief Bioinform. 2019;bbz155. Epub ahead of print.

188. Oliveira FS, Brestelli J, Cade S, Zheng J, lodice J, Fischer S, et al. MicrobiomeDB: a systems biology platform for integrating, mining and analyzing microbiome experiments. Nucleic Acids Res. 2018;46:D684-91 Oxford Academic

189. Giraldo-Calderon GI, Emrich SJ, MacCallum RM, Maslen G, Dialynas E, Topalis $P$, et al. VectorBase: an updated bioinformatics resource for invertebrate vectors and other organisms related with human diseases. Nucleic Acids Res. 2015;43:D707-13.

190. Thurmond J, Goodman JL, Strelets VB, Attrill H, Gramates LS, Marygold SJ, et al. FlyBase 2.0: the next generation. Nucleic Acids Res. 2018;47:D759-65.

191. Yin C, Shen G, Guo D, Wang S, Ma X, Xiao H, et al. InsectBase: a resource for insect genomes and transcriptomes. Nucleic Acids Res. 2016;44:D801-7.

192. Poelchau M, Childers C, Moore G, Tsavatapalli V, Evans J, Lee CY, et al. The i5k Workspace@NAL--enabling genomic data access, visualization and curation of arthropod genomes. Nucleic Acids Res. 2015:43:D714-9.

\section{Publisher's Note}

Springer Nature remains neutral with regard to jurisdictional claims in published maps and institutional affiliations.
Ready to submit your research? Choose BMC and benefit from:
- fast, convenient online submission
- thorough peer review by experienced researchers in your field
- rapid publication on acceptance
- support for research data, including large and complex data types
- gold Open Access which fosters wider collaboration and increased citations
- maximum visibility for your research: over $100 \mathrm{M}$ website views per year
At BMC, research is always in progress.
Learn more biomedcentral.com/submissions 